\title{
Electronic spectra of anions intercalated in layered double hydroxides
}

\author{
S RADHA and P VISHNU KAMATH* \\ Department of Chemistry, Central College, Bangalore University, Bangalore 560 001, India
}

MS received 14 February 2012; revised 4 September 2012

\begin{abstract}
Transition metal complexes intercalated in layered double hydroxides have a different electronic structure as compared to their free state owing to their confinement within the interlayer gallery. UV-Vis absorptions of the intercalated complex anions show a significant shift as compared to their free state. The ligand to metal charge transfer transitions of the ferricyanide anion show a red shift on intercalation. The ferrocyanide ion shows a significant blue shift of $d-d$ bands due to the increased separation between $t_{2 \mathrm{~g}}$ and $e_{\mathrm{g}}$ levels on intercalation. $\mathrm{MnO}_{4}^{-}$ion shows a blue shift in its ligand to metal charge transfer transition since the non-bonding $t_{1}$ level of oxygen from which the transition arises is stabilized.
\end{abstract}

Keywords. Layered double hydroxides; intercalation; electronic spectroscopy.

\section{Introduction}

Layered double hydroxides (LDHs) constitute an important class of inorganic materials which comprise positively charged layers having the composition, $\left[\mathrm{M}_{1-x}^{\mathrm{II}} \mathrm{Al}_{x}(\mathrm{OH})_{2}\right]^{x+}$ ( $x=0.33, \mathrm{M}=\mathrm{Zn}$ in this work), incorporating anions in the interlayer for charge neutrality (Miyata 1975). A typical LDH has the composition, $\left[\mathrm{Zn}_{0.67} \mathrm{Al}_{0.33}(\mathrm{OH})_{2}\right]\left(\mathrm{A}^{n-}\right)_{0.33 / n}$. $\mathrm{yH}_{2} \mathrm{O}\left(\mathrm{A}=\mathrm{CO}_{3}^{2-}, \mathrm{NO}_{3}^{-}, \mathrm{Cl}^{-}\right.$and others). For brevity, we represent this composition with the symbol $\mathrm{Zn}-\mathrm{Al}-\mathrm{A}$. LDHs have gained attention in recent years because of their potential applications in catalysis, drug-delivery, optical devices, bio-sensors and other areas (Cavani et al 1991; Choy et al 1999; Scavetta et al 2007; Costantino et al 2008). LDHs intercalated with transition metal complexes are of interest since their decomposition products are mixed-metal oxides and the third metal component improves activity of oxide catalyst (Rives and Ulibarri 1999).

In LDHs, intercalated species is restricted between the close packed metal hydroxide layers which constrains the degrees of freedom of the intercalated species and further limits the growth of solvation sphere. Complex anions $\left(\left[\mathrm{ML}_{n}\right]^{p-}, \mathrm{M}\right.$ : metal, L: ligand) bond with the hydroxyl groups of the layers and interlayer water through the terminal atom symmetry adapted orbitals (TASOs) of the ligand. TASOs are also involved in bonding with the central metal atom in the transition metal complexes. Hence, one would expect a variation in the electronic structure of the transition metal complex on being confined in the interlayer as opposed to its free state. Transition metal complexes absorb in UVVis region of the electromagnetic spectrum due to (i) $d-d$ transitions in the metal and (ii) charge transfer (CT) transitions $(\mathrm{L} \rightarrow \mathrm{M}$ or $\mathrm{M} \rightarrow \mathrm{L}$ ). It would be interesting to study the effect of intercalation on these two classes of transitions.

\footnotetext{
*Author for correspondence (vishnukamath8@ hotmail.com)
}

There are several studies on the intercalation of cyano-, halo-, oxo-complexes and complexes containing macrocyclic ligands and the changes in optical, magnetic and other properties brought about by intercalation (Giannelis et al 1987; Lopez-Salinas and Ono 1993; Hansen and Koch 1994; Sels et al 1999; Venugopal et al 2006). The intercalation of the hexacyanoferrates of $\mathrm{Fe}(\mathrm{II})$ and $\mathrm{Fe}(\mathrm{III})$ into LDH gallery results in a reaction with the metal hydroxide layers leading to the formation of mixed cation hexacyanoferrates, in which some of the cations come from LDH host (Carpani et al 2006). Raman studies show that molecular symmetry of the hexacyanoferrates changes to $D_{3 \mathrm{~d}}$ on intercalation within LDH (Frost et al 2005). Most of these investigations employ infrared, Mössbauer and X-ray absorption spectroscopies. Fernandez et al (1998) report that diffuse reflectance UV-Vis spectra of intercalated hexacyanoferrates are similar to those of the free ion.

In this paper, we focus on changes in the electronic structure of the complex ions resulting from their intercalation between LDH layers. We choose $\left[\mathrm{Fe}(\mathrm{CN})_{6}\right]^{4-},\left[\mathrm{Fe}(\mathrm{CN})_{6}\right]^{3-}$ (hereafter abbreviated as $\left[\mathrm{Fe}^{\mathrm{II}}\right]$ and $\left[\mathrm{Fe}^{\mathrm{III}}\right]$, respectively) and $\mathrm{MnO}_{4}^{-}$, as model systems for the study of $d-d$ transition and charge transfer transitions, respectively. We intercalate these model anions in $\mathrm{Zn}-\mathrm{Al} \mathrm{LDH}$ and study their UV-Vis spectra.

\section{Experimental}

Precursor $\left[\mathrm{Zn}-\mathrm{Al}-\mathrm{NO}_{3}\right]$ LDH was prepared by a coprecipitation technique, wherein $50 \mathrm{~mL}$ of a mixed metal nitrate solution $\left(\left[\mathrm{Zn}^{2+}\right] /\left[\mathrm{Al}^{3+}\right]=2\right.$, total concentration $0.44 \mathrm{M}$ ) was added drop wise to a reaction vessel containing $100 \mathrm{~mL}$ of $\mathrm{NaNO}_{3}$ salt solution taken 5 times in excess of stoichiometric requirement. A constant $\mathrm{pH}$ of 8 was maintained during preparation by adding $0.25 \mathrm{M} \mathrm{NaOH}$ solution using Metrohm model 718 STAT Titrino operating in the $\mathrm{pH}$ 
STAT mode. $\mathrm{N}_{2}$ gas was bubbled throughout the preparation and the temperature was maintained at $60{ }^{\circ} \mathrm{C}$. The slurry obtained was aged for $16 \mathrm{~h}$, separated by centrifugation and washed with warm water saturated with $\mathrm{N}_{2}$.

For the preparation of $\mathrm{Zn}-\mathrm{Al}-\mathrm{A}\left(\mathrm{A}=\left[\mathrm{Fe}(\mathrm{CN})_{6}\right]^{3-}\right.$, $\left.\left[\mathrm{Fe}(\mathrm{CN})_{6}\right]^{4-},\left[\mathrm{MnO}_{4}\right]^{-}\right) \mathrm{LDHs}$, about $0.5 \mathrm{~g}$ of $\mathrm{Zn}-\mathrm{Al}-\mathrm{NO}_{3}$, LDH precursor was dispersed in a solution containing potassium salt of the anion (10 times excess of the stoichiometric requirement) which is presaturated with $\mathrm{N}_{2}$ and stirred for $40 \mathrm{~h}$. The reaction vessel was covered with aluminum foil in order to prevent unwanted photolytic reactions and the precipitate obtained is washed with warm decarbonated water saturated with $\mathrm{N}_{2}$. The products obtained were dried in a desiccator and stored in the dark to prevent all redox reactions of the intercalated species (Boclair et al 2001). The metal contents of the samples were determined by atomic absorption spectroscopy (Varian Model AA240 Atomic Absorption Spectrometer). Samples were digested in acid and total iron content in the case of ferrocyanide/ferricyanide and the total manganese content in the permanganate intercalated sample were determined along with $\mathrm{Zn}$ and $\mathrm{Al}$ contents. Thermogravimetric studies were carried out using Mettler Toledo $851^{\mathrm{e}}$ TGA/SDTA system. Samples were dried at $100{ }^{\circ} \mathrm{C}$ for $30 \mathrm{~min}$ in $\mathrm{TG}$ balance to expel adsorbed water and the temperature was ramped from $100-800{ }^{\circ} \mathrm{C}$ $\left(5^{\circ} \mathrm{C} \min ^{-1} ; \mathrm{N}_{2}\right.$ atmosphere). The low temperature $\left(T<200^{\circ} \mathrm{C}\right)$ mass loss yielded intercalated water content of LDHs. From the intercalated anion content and TGA data, approximate formulae of LDHs were determined (table 1). $\mathrm{Zn}$ and $\mathrm{Al}$ contents in the formulae were adjusted to balance the negative charge due to the estimated content of the intercalated anion. However, this does not match with the actual $\mathrm{Zn}$ content estimated by AAS and hence, the formulae given in table 1, are approximate. This divergence was due to $\mathrm{Zn}$ dissolution by leaching during anion exchange.

PXRD patterns of all the samples were recorded using Bruker D8 Advance powder diffractometer (source $\mathrm{CuK} \alpha$ radiation, $\lambda=1.5418 \AA$ ), at a scan rate of $1^{\circ} 2 \theta \mathrm{min}^{-1}$. IR spectra of the samples were obtained using Shimadzu FTIR$8400 \mathrm{~S}$ spectrophotometer $\left(\mathrm{KBr}\right.$ pellets, $4 \mathrm{~cm}^{-1}$ resolution, $400-4000 \mathrm{~cm}^{-1}$ ). Diffused reflectance UV-Vis absorption spectra were obtained using Shimadzu ISR-3100 UV-VisNIR scanning spectrophotometer. The spectra were recorded from $200-800 \mathrm{~nm}$ at a scan rate of $0.83 \mathrm{~nm} \mathrm{~s}^{-1}$. Where overlapping bands are observed, these are deconvoluted into Gaussian components using Peakfit (2007) version 4.12 software (Peakfit SeaSolve Software). UV-Vis spectrum of the precursor $\mathrm{Zn}-\mathrm{Al}-\mathrm{NO}_{3} \mathrm{LDH}$ was recorded to ensure that there was no absorption due to the host $\mathrm{LDH}$ in the region, where the absorptions due to the anions $\left(\left[\mathrm{Fe}(\mathrm{CN})_{6}\right]^{3-}\right.$, $\left.\left[\mathrm{Fe}(\mathrm{CN})_{6}\right]^{4-},\left[\mathrm{MnO}_{4}\right]^{-}\right)$are expected. So the observed spectra were solely due to the intercalated species.

\section{Results and discussion}

\subsection{Ferricyanide, ferrocyanide intercalated LDHs}

PXRD patterns obtained for $\mathrm{Zn}-\mathrm{Al}-\left[\mathrm{Fe}^{\mathrm{II}}\right]$ and $\mathrm{Zn}-\mathrm{Al}-\left[\mathrm{Fe}^{\mathrm{III}}\right]$ LDHs are shown along with that of $\mathrm{Zn}-\mathrm{Al}-\mathrm{NO}_{3} \mathrm{LDH}$ in figure 1 . Increase in the basal spacing from $8.8 \AA$ in $\mathrm{NO}_{3}^{-}-$ LDH to $11 \AA$ in the case of ferricyanide-LDH and $10.89 \AA$ in the case of ferrocyanide-LDH upon exchange, confirms the intercalation of these species into LDH gallery. XRD peaks obtained in the case of ferricyanide intercalated LDH could be indexed to a phase with rhombohedral symmetry ( $a=$ $3.075 \AA$ and $c=32.9 \AA$ ). Further, IR spectra (figure 2) confirm intercalation of the ions into $\mathrm{LDH}$. $\mathrm{Zn}-\mathrm{Al}-\left[\mathrm{Fe}^{\mathrm{III}}\right] \mathrm{LDH}$ shows a band at $2112 \mathrm{~cm}^{-1}$ characteristic of $\mathrm{C} \equiv \mathrm{N}$ stretch with $\mathrm{Fe}$ in +3 oxidation state, whereas $\mathrm{Zn}-\mathrm{Al}-\left[\mathrm{Fe}^{\mathrm{II}}\right] \mathrm{LDH}$ shows a band at $2025 \mathrm{~cm}^{-1}$. The frequency of $\mathrm{C} \equiv \mathrm{N}$ stretch is highly sensitive to oxidation state of the iron in the complex (Tosi and Danon 1964). Absence of the band at $2040 \mathrm{~cm}^{-1}$ in the spectrum of $\mathrm{Zn}-\mathrm{Al}-\left[\mathrm{Fe}^{\mathrm{III}}\right] \mathrm{LDH}$ suggests that there is no reduction of $\mathrm{Fe}(\mathrm{III})$ to $\mathrm{Fe}(\mathrm{II})$ as reported earlier (Idemura et al 1989; Fernandez et al 1998). Similarly, absence of band in the region of $2110 \mathrm{~cm}^{-1}$ in the case of $\mathrm{Zn}-\mathrm{Al}-\left[\mathrm{Fe}^{\mathrm{II}}\right] \mathrm{LDH}$ indicates that there is no oxidation of $\mathrm{Fe}$ (II) to $\mathrm{Fe}$ (III).

The composition of the precursor and anion-exchanged LDHs are given in table $1 . \mathrm{Zn} / \mathrm{Al}$ ratio in the precursor LDHs is close to 2 and upon exchange with the complexes there is a decrease in the ratio, which may be attributed to dissolution of $\mathrm{LDH}$ during exchange. $\mathrm{Al} / \mathrm{Fe}$ ratios show that in both $\mathrm{Zn}-\mathrm{Al}-\left[\mathrm{Fe}^{\mathrm{III}}\right]$ and $\mathrm{Zn}-\mathrm{Al}-\left[\mathrm{Fe}^{\mathrm{II}}\right] \mathrm{LDH}$ the iron content is less than the stoichiometric requirement. This suggests the presence of residual nitrate in the exchanged samples which is evident in IR spectra.

TGA data overlaid with DTG curve for $\mathrm{Zn}-\mathrm{Al}-\left[\mathrm{Fe}^{\mathrm{III}}\right]$ and $\mathrm{Zn}-\mathrm{Al}-\left[\mathrm{Fe}^{\mathrm{II}}\right] \mathrm{LDHs}$ are shown in figure 3. The mass loss observed below $200{ }^{\circ} \mathrm{C}$ is attributed to the removal of intercalated water. The water content present in the sample is found to be 0.68 moles per formula unit in the case of $\mathrm{Zn}-\mathrm{Al}-\left[\mathrm{Fe}^{\mathrm{III}}\right]$

Table 1. Results of wet-chemical analysis and TGA of LDHs used.

\begin{tabular}{|c|c|c|c|c|}
\hline LDH & $\mathrm{Zn} / \mathrm{Al}$ & $\mathrm{Al} / \mathrm{Fe}(\mathrm{Mn})$ & Water content & Approximate formula \\
\hline $\mathrm{Zn}-\mathrm{Al}-\mathrm{NO}_{3}$ & $2 \cdot 1$ & - & 0.72 & $\mathrm{Zn}_{0.67} \mathrm{Al}_{0.32}(\mathrm{OH})_{2} \cdot 0 \cdot 72 \mathrm{H}_{2} \mathrm{O}$ \\
\hline $\mathrm{Zn}-\mathrm{Al}-\left[\mathrm{Fe}^{\mathrm{III}}\right]$ & $2 \cdot 06$ & $3 \cdot 4(3 \cdot 0)^{*}$ & 0.68 & $\mathrm{Zn}_{0.67} \mathrm{Al}_{0.32}(\mathrm{OH})_{2}\left[\mathrm{Fe}(\mathrm{CN})_{6}\right]_{0.094} \cdot 0.68 \mathrm{H}_{2} \mathrm{O}$ \\
\hline $\mathrm{Zn}-\mathrm{Al}-\left[\mathrm{Fe}^{\mathrm{II}}\right]$ & 1.7 & $4 \cdot 5(4 \cdot 0)$ & 0.64 & $\mathrm{Zn}_{0.60} \mathrm{Al}_{0.32}(\mathrm{OH})_{2}\left[\mathrm{Fe}(\mathrm{CN})_{6}\right]_{0.071} \cdot 0.64 \mathrm{H}_{2} \mathrm{O}$ \\
\hline $\mathrm{Zn}-\mathrm{Al}-\mathrm{MnO}_{4}$ & $1 \cdot 8$ & $0 \cdot 9(1 \cdot 0)$ & $0 \cdot 54$ & $\mathrm{Zn}_{0.60} \mathrm{Al}_{0.32}(\mathrm{OH})_{2}\left[\mathrm{MnO}_{4}\right]_{0.03} \cdot 0 \cdot 54 \mathrm{H}_{2} \mathrm{O}$ \\
\hline
\end{tabular}

*Numbers given in parentheses are expected values. 


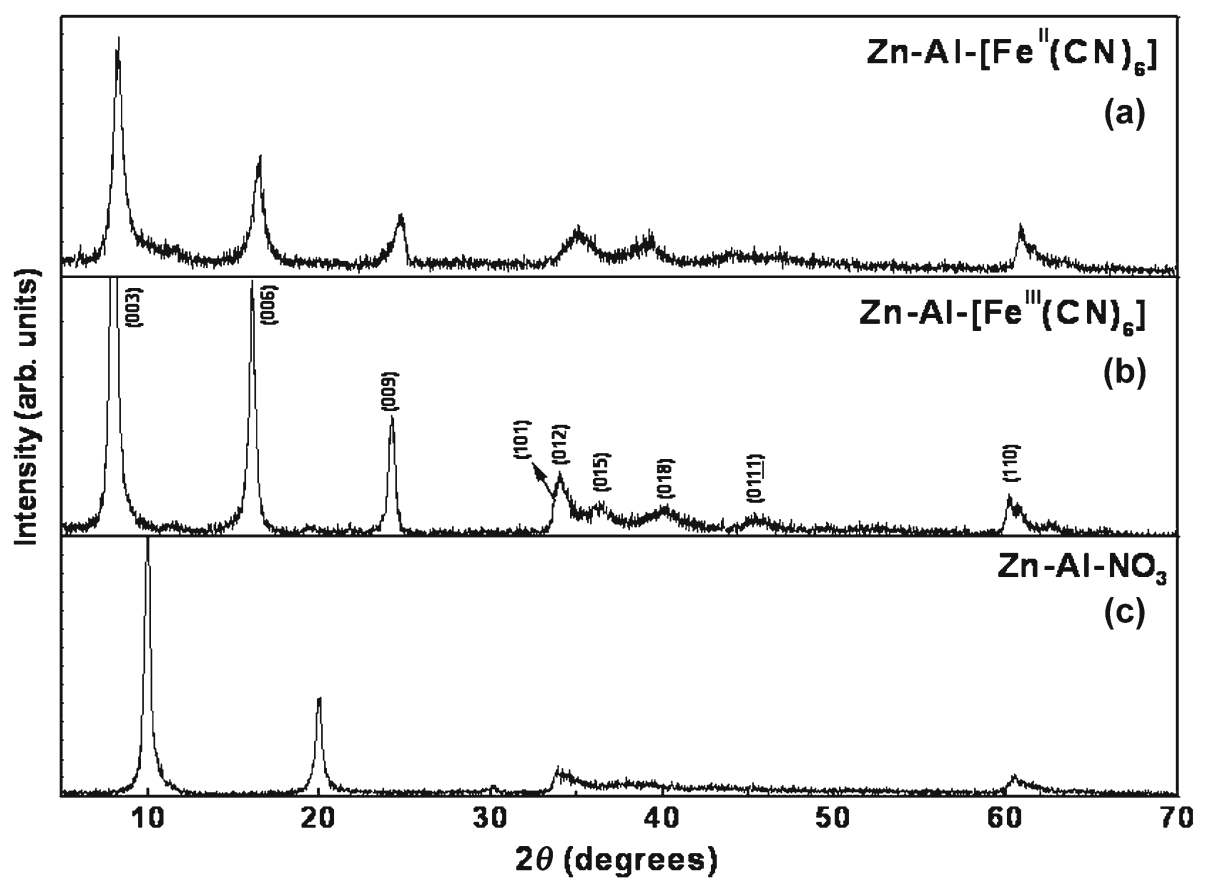

Figure 1. PXRD patterns of (a) $\mathrm{Zn}-\mathrm{Al}-\mathrm{NO}_{3}$, (b) $\mathrm{Zn}-\mathrm{Al}-\left[\mathrm{Fe} e^{\mathrm{III}}(\mathrm{CN})_{6}\right]$ and (c) $\mathrm{Zn}-\mathrm{Al}-$ $\left[\mathrm{Fe}^{\mathrm{II}}(\mathrm{CN})_{6}\right]$ LDHs.

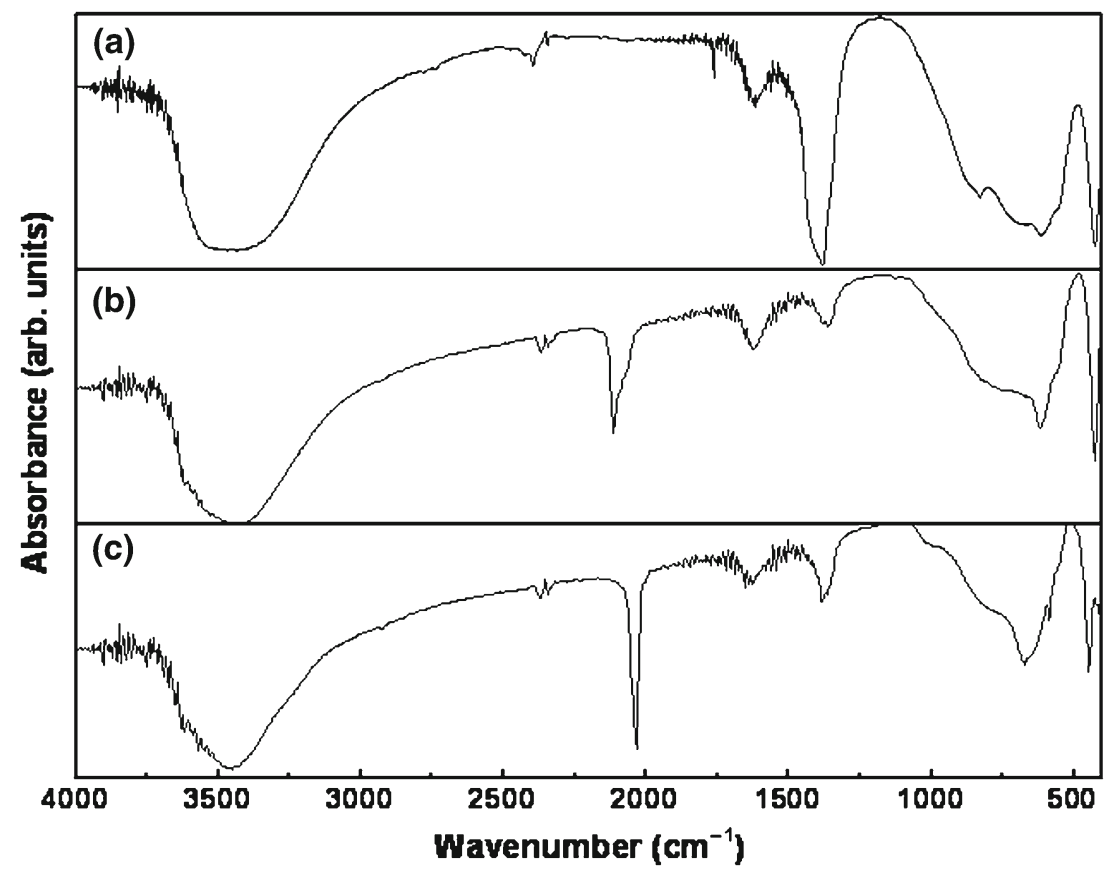

Figure 2. IR spectra of (a) $\mathrm{Zn}-\mathrm{Al}-\mathrm{NO}_{3}$, (b) $\mathrm{Zn}-\mathrm{Al}-\left[\mathrm{Fe}^{\mathrm{III}}(\mathrm{CN})_{6}\right]$ and (c) $\mathrm{Zn}-\mathrm{Al}-$ $\left[\mathrm{Fe}^{\mathrm{II}}(\mathrm{CN})_{6}\right]$ LDHs.

and 0.64 moles per formula unit in the case of $\mathrm{Zn}-\mathrm{Al}-\left[\mathrm{Fe}^{\mathrm{II}}\right]$ LDH.

A comparison of UV-Vis spectrum of $\mathrm{Zn}-\mathrm{Al}-\left[\mathrm{Fe}^{\mathrm{III}}\right] \mathrm{LDH}$ with that of pure salt (figure 4) shows that all the bands are shifted to a lower energy and the extent of shift of each band is listed in table 2. The bands observed for $\mathrm{K}_{3}\left[\mathrm{Fe}(\mathrm{CN})_{6}\right]$ are assigned according to Alexander and Gray (1968). In $\left[\mathrm{Fe}(\mathrm{CN})_{6}\right]^{3-}$, iron is in $d^{5}$ configuration with a hole in $t_{2 \mathrm{~g}}$ level, which permits ligand to metal charge transfer (LMCT), which are intense transitions, along with weak $d-d$ bands. LMCT to metal $t_{2 \mathrm{~g}}$ level are observed in UV-Vis region, whereas LMCT transitions to the metal $e_{\mathrm{g}}$ level lie in the 


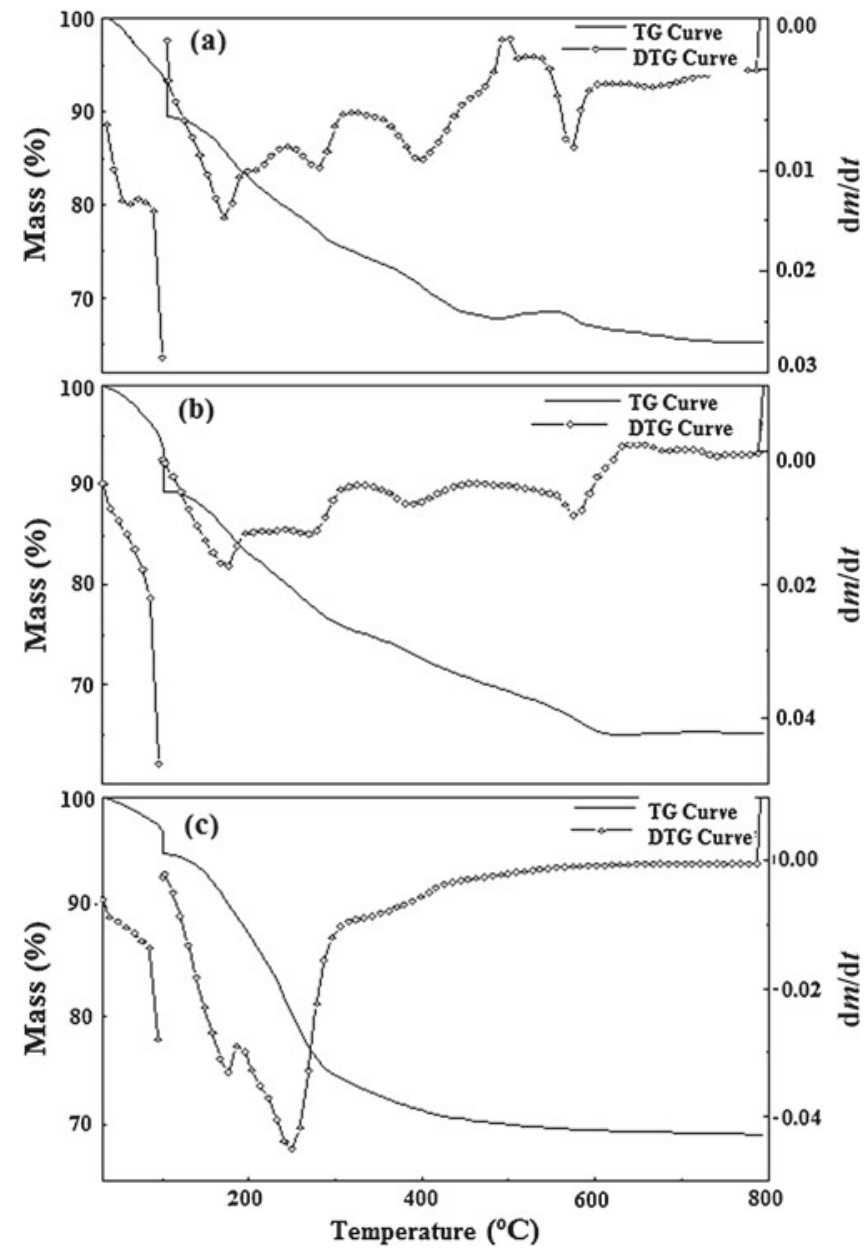

Figure 3. TG-DTG curves of (a) $\mathrm{Zn}-\mathrm{Al}-\left[\mathrm{Fe}^{\mathrm{III}}(\mathrm{CN})_{6}\right]$, (b) $\mathrm{Zn}-$ $\mathrm{Al}-\left[\mathrm{Fe}^{\mathrm{II}}(\mathrm{CN})_{6}\right] \mathrm{LDHs}$ and (c) $\mathrm{Zn}-\mathrm{Al}-\mathrm{MnO}_{4} \mathrm{LDH}$. The mass loss at $100{ }^{\circ} \mathrm{C}$ is due to in situ drying $\left(100{ }^{\circ} \mathrm{C}, 30 \mathrm{~min}\right.$ stay $)$.

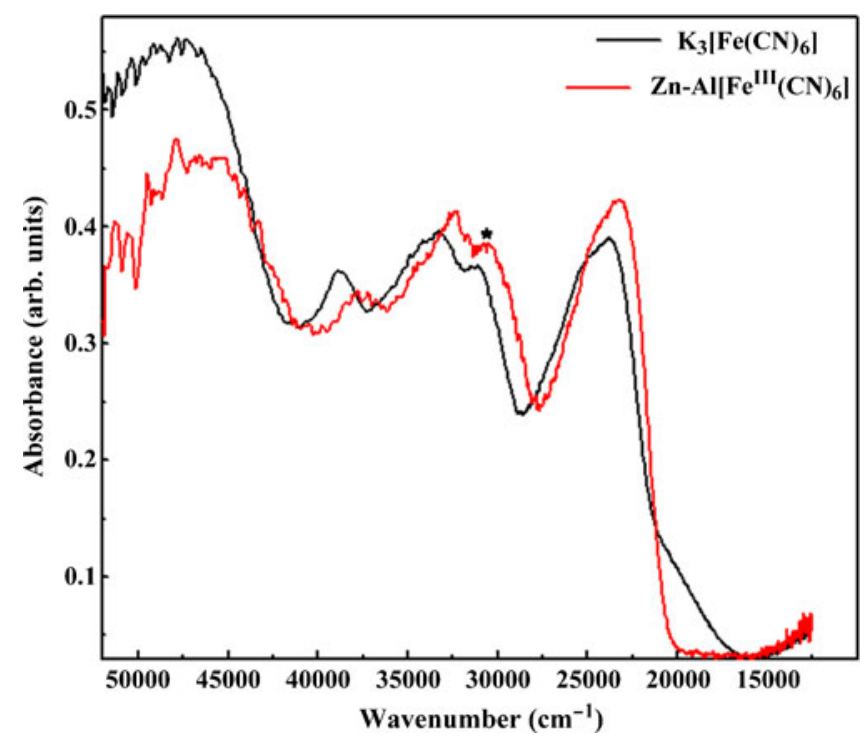

Figure 4. UV-Visible spectra of $\mathrm{Zn}-\mathrm{Al}-\left[\mathrm{Fe}^{\mathrm{III}}(\mathrm{CN})_{6}\right] \mathrm{LDH}$ overlaid with that of $\mathrm{K}_{3}\left[\mathrm{Fe}(\mathrm{CN})_{6}\right]$. Feature marked with an asterisk is due to $d-d$ transition. vacuum UV region. The bands at 38,700, 33,250, $23,740 \mathrm{~cm}^{-1}$ in $\mathrm{K}_{3}\left[\mathrm{Fe}(\mathrm{CN})_{6}\right]$ are assigned to LMCT from low lying ligand orbitals to metal $t_{2 \mathrm{~g}}$. These transitions in LDH shift to red and are observed at 37,650, 32,325 and $23,170 \mathrm{~cm}^{-1}$. The weak band corresponding to $31,200 \mathrm{~cm}^{-1}$ $\left(30,366 \mathrm{~cm}^{-1}\right.$ on intercalation) is assigned to $d-d$ transition.

Similar data of $\mathrm{Zn}-\mathrm{Al}-\left[\mathrm{Fe}^{\mathrm{II}}\right] \mathrm{LDH}$ show that the absorptions due to intercalated $\left[\mathrm{Fe}(\mathrm{CN})_{6}\right]^{4-}$ ion are shifted to higher wavenumbers compared to pure salt (figure 5). The bands observed are assigned according to Gray and Beach (1963). In $\left[\mathrm{Fe}(\mathrm{CN})_{6}\right]^{4-}$, iron is in $d^{6}$ configuration and since, $\mathrm{CN}^{-}$is a strong field ligand, it forms low spin complex with $t_{2 \mathrm{~g}}$ level completely filled to give ${ }^{1} A_{1 \mathrm{~g}}$ ground state with the configuration $\left(3 t_{1 \mathrm{u}}\right)^{6}\left(2 t_{2 \mathrm{~g}}\right)^{6}$. All LMCT transition from low lying ligand orbitals must terminate on the high energy $e_{\mathrm{g}}$ level and these would appear in the vacuum UV region. On the other hand, metal to ligand charge transfer (MLCT) transitions from $t_{2 \mathrm{~g}}$ to anti-bonding ligand orbitals are expected and they are commonly observed (Lever 1985). The overlapping bands observed in $\mathrm{K}_{4}\left[\mathrm{Fe}(\mathrm{CN})_{6}\right]$ and $\mathrm{Zn}-\mathrm{Al}-\left[\mathrm{Fe}^{\mathrm{II}}\right] \mathrm{LDH}$ are decomposed into Gaussian components and the absorption maxima and FWHM values of the constituent Gaussian bands are listed in table 3. The absorption observed at $29,761 \mathrm{~cm}^{-1}$ in $\mathrm{K}_{4}\left[\mathrm{Fe}(\mathrm{CN})_{6}\right]$ is assigned to $d-d$ transition from $2 t_{2 \mathrm{~g}} \rightarrow 3 e_{\mathrm{g}}$, which in the case of LDH shifts towards blue and is observed at $30,950 \mathrm{~cm}^{-1}$. The band observed at $44,050 \mathrm{~cm}^{-1}$ in $\mathrm{K}_{4}\left[\mathrm{Fe}(\mathrm{CN})_{6}\right]$ is assigned to one of the $\mathrm{CT}$ transitions from metal to ligand which does not show much shift on intercalation. The weak band observed at $\sim 36,000 \mathrm{~cm}^{-1}$ is assigned to be the other $d-d$ transition which in the LDH sample is masked by the strong CT band and on peak, decomposition is observed at $38,314 \mathrm{~cm}^{-1}$.

\section{$3.2 \mathrm{MnO}_{4}^{-}$containing $\mathrm{LDH}$}

PXRD pattern and the corresponding IR spectrum of $\mathrm{Zn}-$ $\mathrm{Al}-\mathrm{MnO}_{4}^{-} \mathrm{LDH}$ are shown in figure 6. The diminished $\mathrm{NO}_{3}^{-}$ peak at $1380 \mathrm{~cm}^{-1}$ in IR spectrum and the appearance of a peak at $910 \mathrm{~cm}^{-1}$ indicates that $\mathrm{MnO}_{4}^{-}$is intercalated in the interlayer (Villegas et al 2003). TG data obtained for LDH overlaid with DTG curve (figure 3) indicates three mass loss steps. The mass loss below $200{ }^{\circ} \mathrm{C}$ is attributed to the removal of adsorbed and intercalated water. The amount of water present in the interlayer of LDH is found to be 0.54 moles per unit formula (table 1). UV-Vis spectrum of $\mathrm{MnO}_{4}^{-} \mathrm{LDH}$ is compared with that of $\mathrm{KMnO}_{4}$ (figure 7). The overlapping bands in the spectra are decomposed into their Gaussian components. The bands observed for $\mathrm{KMnO}_{4}$ are assigned according to Viste and Gray (1964). In $\mathrm{MnO}_{4}^{-}$, $\mathrm{Mn}$ is in $d^{0}$ configuration and all the bands observed are due to $\mathrm{L} \rightarrow \mathrm{M}$ charge transfer transitions. Three prominent bands are seen in UV-Vis spectrum of $\mathrm{KMnO}_{4}$ and are observed at $31,347,18,939$ and $14,662 \mathrm{~cm}^{-1}$. The intense band observed at $31,347 \mathrm{~cm}^{-1}$ is assigned to $3 t_{2} \rightarrow 2 e$ transition, whereas the band observed at $18,939 \mathrm{~cm}^{-1}$ is assigned to $t_{1} \rightarrow 2 e$ transition and the band at $14,662 \mathrm{~cm}^{-1}$ to the spin-forbidden 

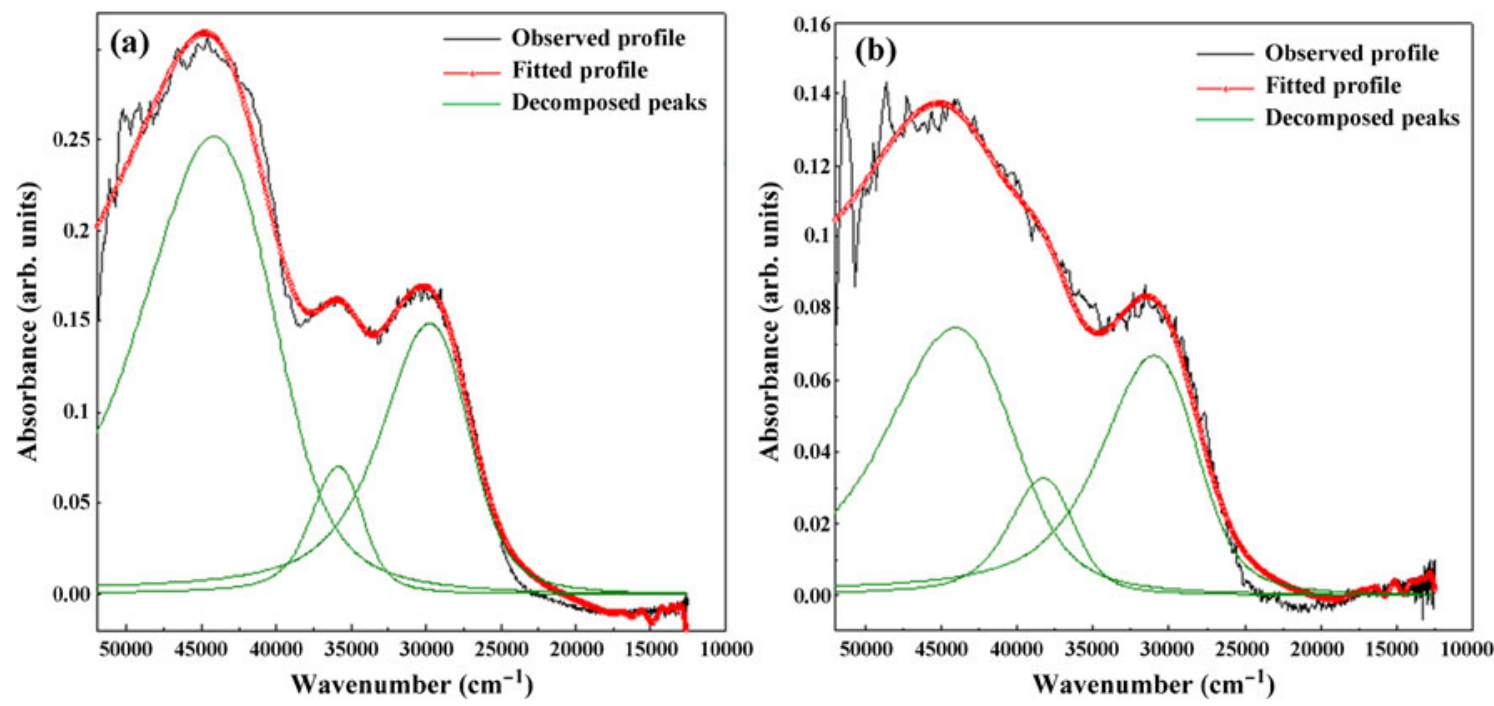

Figure 5. UV-Visible spectra of $(\mathbf{a}) \mathrm{K}_{4}\left[\mathrm{Fe}(\mathrm{CN})_{6}\right]$ and $(\mathbf{b}) \mathrm{Zn}-\mathrm{Al}-\left[\mathrm{Fe}^{\mathrm{II}}(\mathrm{CN})_{6}\right]$ LDHs with their decomposed Gaussian components.

Table 2. List of band positions observed for potassium salts of anion and LDH samples.

\begin{tabular}{lccc}
\hline Salts & Peak position $\left(\mathrm{cm}^{-1}\right)$ & LDH & Peak position $\left(\mathrm{cm}^{-1}\right)$ \\
\hline $\mathrm{K}_{3}\left[\mathrm{Fe}(\mathrm{CN})_{6}\right]$ & 38,700 & $\mathrm{Zn}-\mathrm{Al}-\mathrm{Fe}^{\mathrm{III}}(\mathrm{CN})_{6}$ & 37,650 \\
& 33,250 & & 32,325 \\
& $31,200(d-d)$ & & 30,366 \\
& 23,740 & & 23,170 \\
$\mathrm{~K}_{4}\left[\mathrm{Fe}(\mathrm{CN})_{6}\right]$ & 44,050 & $\mathrm{Zn}-\mathrm{Al}-\mathrm{Fe}^{\mathrm{II}}(\mathrm{CN})_{6}$ & 44,052 \\
& $35,842(d-d)$ & & 38,314 \\
$\mathrm{KMnO}_{4}$ & $29,761(d-d)$ & & 30,950 \\
& 31,347 & $\mathrm{Zn}-\mathrm{Al}-\mathrm{MnO}_{4}$ & 31,387 \\
& 18,939 & & 23,758 \\
& 14,662 & & 18,695 \\
\hline
\end{tabular}

Table 3. List of band centres and FWHM values obtained after decomposition of the observed UV-Vis spectra.

\begin{tabular}{lcc}
\hline Samples & Peak centre $(\mathrm{nm})$ & FWHM values $(\mathrm{nm})$ \\
\hline $\mathrm{K} 4\left[\mathrm{Fe}(\mathrm{CN})_{6}\right]$ & $227 \cdot 0$ & $65 \cdot 3$ \\
& $279 \cdot 1$ & $65 \cdot 3$ \\
$\mathrm{Zn}-\mathrm{Al}-\mathrm{Fe}(\mathrm{CN})_{6}$ & $336 \cdot 2$ & $65 \cdot 3$ \\
& $227 \cdot 7$ & $71 \cdot 6$ \\
& $261 \cdot 8$ & $71 \cdot 6$ \\
$\mathrm{KMnO}_{4}$ & $323 \cdot 1$ & $71 \cdot 6$ \\
& $319 \cdot 0$ & $169 \cdot 6$ \\
$\mathrm{Zn}-\mathrm{Al}-\mathrm{MnO}_{4}$ & $528 \cdot 6$ & $169 \cdot 6$ \\
& $682 \cdot 5$ & $169 \cdot 6$ \\
& $318 \cdot 6$ & $125 \cdot 1$ \\
& $420 \cdot 9$ & $125 \cdot 1$ \\
& 534.9 & $125 \cdot 1$ \\
\hline
\end{tabular}

$t_{1} \rightarrow 2 e$ transition. In $\mathrm{MnO}_{4}^{-}-\mathrm{LDH}$, a single broad asymmetric band is observed indicating the overlapping of bands which upon decomposition into Gaussian components yields absorptions at $31,387,23,758$ and $18,695 \mathrm{~cm}^{-1}$. While the latter two bands are blue shifted compared to $\mathrm{KMnO}_{4}$ bands, the first band at $31,387 \mathrm{~cm}^{-1}$ remains almost at the same position.

The interaction between the metal hydroxide layer and the interlayer species in layered double hydroxides is governed mainly by two kinds of interactions: (i) electrostatic interactions and (ii) hydrogen bonding with the layer hydroxyl groups and with water molecules of the interlayer, which get incorporated into interlayer during the course of preparation. These interactions substantially affect the electronic structure of the intercalated ions by perturbation of TASOs.

In the case of $\left[\mathrm{Fe}(\mathrm{CN})_{6}\right]^{3-}$ and $\left[\mathrm{Fe}(\mathrm{CN})_{6}\right]^{4-}$, the $\mathrm{CN}^{-}$ group is coordinated to $\mathrm{Fe}$ through $\mathrm{C}$ and $\mathrm{N}$ is the free 

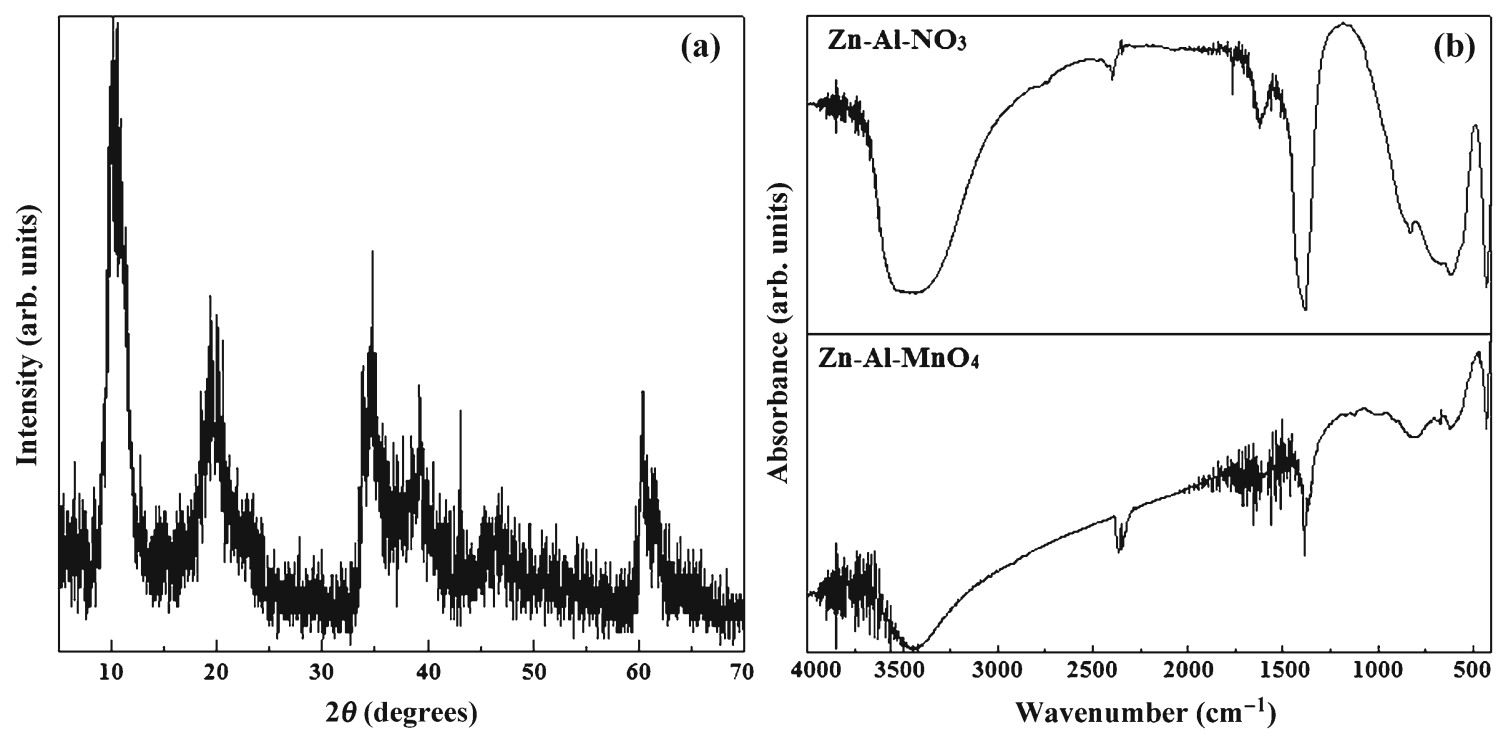

Figure 6. (a) PXRD pattern of $\mathrm{Zn}-\mathrm{Al}-\mathrm{MnO}_{4} \mathrm{LDH}$, (b) IR spectra of $\mathrm{Zn}-\mathrm{Al}-\mathrm{NO}_{3}$ and $\mathrm{Zn}-\mathrm{Al}-\mathrm{MnO}_{4} \mathrm{LDHs}$.
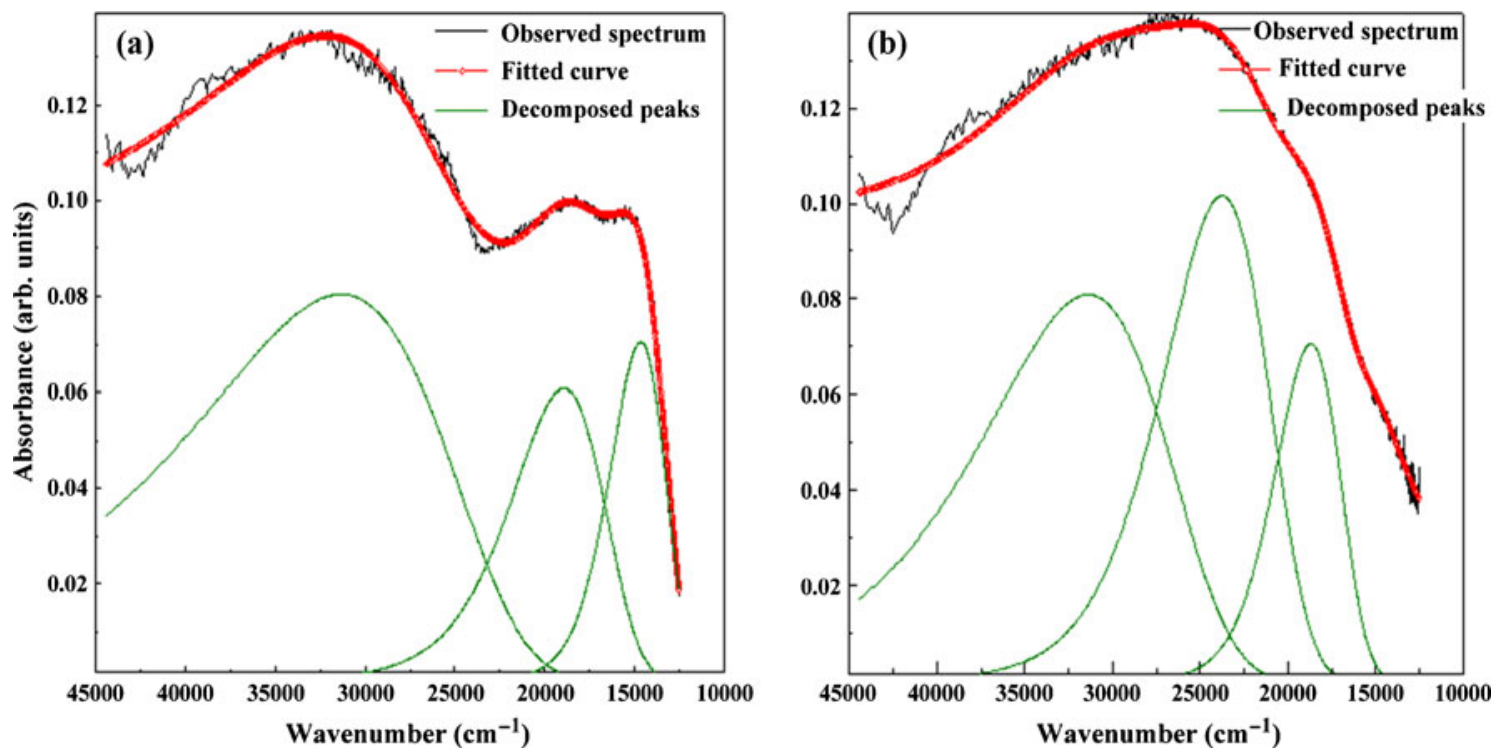

Figure 7. UV-Visible spectra of (a) $\mathrm{KMnO}_{4}$ and (b) $\mathrm{Zn}-\mathrm{Al}-\mathrm{MnO}_{4} \mathrm{LDH}$ with their decomposed Gaussian components.

end. $\mathrm{CN}^{-}$is a strong $\sigma$-donor and a weak $\pi$-acceptor ligand. Upon intercalation into LDH gallery, the free end of the ligand, $\mathrm{CN}^{-}$is involved in hydrogen bonding with the layer hydroxyls and the water molecules of the interlayer. This causes a decrease in electron density on the ligand group orbitals, TASOs and hence, reduces $\sigma$-donor character of the ligand while increasing its $\pi$-acceptor character (Shriver and Posner 1966). This increases the ligand field strength and hence, the separation between $e_{\mathrm{g}}$ and $t_{2 \mathrm{~g}}$ levels. So all LMCT transitions to $t_{2 \mathrm{~g}}$ levels are expected to experience a red shift, while transitions to $e_{\mathrm{g}}$ level are expected to be blue shifted. Further, the $d-d$ and MLCT transitions arising from $t_{2 \mathrm{~g}}$ level are expected to be blue shifted.

In ferricyanide ion, as mentioned earlier, the $d-d$ transitions are weak and are further obscured by intense CT bands arising from low lying ligand orbitals to metal $t_{2 \mathrm{~g}}$ level. On intercalation into LDH, LMCT bands are observed to undergo a red shift as expected.

In case of the ferrocyanide ion, two $d-d$ transitions and one MLCT transition are observed. The two $d-d$ transition bands are shifted to blue in $\mathrm{LDH}$ compared to $\mathrm{K}_{4} \mathrm{Fe}(\mathrm{CN})_{6}$ as expected. The other band observed at $44,052 \mathrm{~cm}^{-1}$ is $\mathrm{M} \rightarrow \mathrm{L}$ CT transition and does not show much shift in its position in $\mathrm{LDH}$ sample and the reason is not clear.

In $\mathrm{MnO}_{4}^{-}$, all the transitions are from non-bonding $p \pi$ orbital $\left(t_{1}\right)$ of oxygen and $3 t_{2}$ level of oxygen to $\sigma$ antibonding orbital of Mn. Upon intercalation into $\mathrm{LDH}$ gallery, the non-bonding $p \pi$ electrons are involved in hydrogen bonding with hydroxyl groups of the metal hydroxide layer and water molecules present in the interlayer, which 
stabilizes the energy of $t_{1}$ level. This being the case one expects a blue shift in the transition arising from this level. In the case of LDH sample, a single broad, asymmetric band is observed. Two CT bands of LDH $\left(23,758\right.$ and $\left.18,695 \mathrm{~cm}^{-1}\right)$ are from non-bonding $p \pi$ orbital of oxygen to $\sigma$-antibonding level of Mn and are indeed blue shifted. The other band at $31,387 \mathrm{~cm}^{-1}$ is due to transition from $3 t_{2}$ of oxygen to $\sigma$ antibonding orbital of $\mathrm{Mn}$. Since, $3 t_{2}$ orbital of $\mathrm{MnO}_{4}^{-}$is less involved in any of the interactions with the interlayer, this band remains invariant.

Apart from the factors discussed above, there are several other factors that influence the observed UV-Vis spectra of LDH samples, which are highly complicated to predict. Further, the extent of shift observed is not explained since it requires the quantification of various interactions involved.

\section{Conclusions}

We report here transition metal complex intercalated LDHs and study the effect of intercalation on their UV-Vis bands for which, we have chosen ferrocyanide/ferrocyanide and permanganate ions as candidate anions for $d-d$ and CT transitions, respectively. Shift in the position of UV-Vis bands is observed in all the cases. We interpret the shift in bands based on the variation in ligand field strength of the metal complex upon intercalation into LDH interlayer due to various interactions involved with the host.

\section{Acknowledgements}

The authors thank Prof E Arunan for useful discussions and the Department of Science and Technology (DST), Government of India (GOI), for financial support. (S R) is grateful to the Council for Scientific and Industrial Research, GOI, for the award of a senior research fellowship. (PVK) is a recipient of the Ramanna fellowship of DST.

\section{References}

Alexander J J and Gray H B 1968 J. Am. Chem. Soc. 90 4260

Boclair J W, Braterman P S, Brister B D, Wang Z and Yarberry F 2001 J. Solid State Chem. 161249

Carpani I, Berrettoni M, Giorgetti M and Tonelli D 2006 J. Phys. Chem. B110 7265

Cavani F, Trifiro F and Vaccari A 1991 Catal. Today 11173

Choy J H, Kwak S Y, Park J S, Jeong Y J and Portier J 1999 J. Am. Chem. Soc. 1211399

Costantino U, Ambrogi V, Nocchetti M and Perioli L 2008 Micropor. Mesopor. Mater. 107149

Fernandez J M, Ulibarri M A, Labajos F M and Rives V 1998 J. Mater. Chem. 82507

Frost R L, Musumeci A W, Bouzaid J, Adebajo M O, Martens W N and Kloprogge J T 2005 J. Solid State Chem. 1781940

Giannelis E P, Nocera D G and Pinnavaia T J 1987 Inorg. Chem. 26203

Gray H B and Beach N A 1963 J. Am. Chem. Soc. 852922

Hansen H C B and Koch C B 1994 Clays Clay Miner. 42170

Idemura S, Suzuki E and Ono Y 1989 Clays Clay Miner. 37553

Lever A B P 1985 Inorganic electronic spectroscopy (ed.) M F Lappert (London: Elsevier)

Lopez-Salinas E and Ono Y 1993 Micropor. Mater. 133

Miyata S 1975 Clays Clay Miner. 23369

Peakfit Software (2007) Version 4.12 SeaSolve Software Inc., 235 Walnut St., Suite Framingham, MA 01702

Rives V and Ulibarri M A 1999 Coord. Chem. Rev. 18161

Scavetta E, Scavetta S, Stipa S, Stipa D and Tonelli D 2007 Electrochem. Commun. 92838

Sels B F, De Vos D E, Grobet J P, Pierard F, Mesmaeker F K D and Jacobs P A 1999 J. Phys. Chem. B103 1111

Shriver D F and Posner J 1966 J. Am. Chem. Soc. 881672

Tosi L and Danon J 1964 Inorg. Chem. 3150

Venugopal B R, Ravishankar N, Christopher Perrey R, Shivakumara C and Michael Rajamathi 2006 J. Phys. Chem. B110 772

Villegas J C, Giraldo O H, Laubernds K and Suib S L 2003 Inorg. Chem. 425621

Viste A and Gray H B 1964 J. Am. Chem. Soc. 861113 